\title{
Overview of Treatment of Pediatric Acute-Onset Neuropsychiatric Syndrome
}

\author{
Susan E. Swedo, MD, Jennifer Frankovich, MD, MS, ${ }^{2,3}$ and Tanya K. Murphy, MD, MS ${ }^{4}$
}

Keywords: pediatric acute-onset neuropsychiatric syndrome, pediatric autoimmune neuropsychiatric disorder associated with streptococcal infections, overview of PANS/PANDAS treatments, treatment with antibiotics, treatment with antiinflammatory or immune modulating therapies, treatment with psychiatric medications and behavioral interventions

$\mathbf{P}$ ediatric Acute-onset Neuropsychiatric Syndrome (PANS) is a clinical condition defined by the unusually abrupt onset of obsessive-compulsive symptoms and/or severe eating restrictions and at least two concomitant cognitive, behavioral, or neurological symptoms (Swedo et al. 2012). Because the PANS criteria define a broad spectrum of neuropsychiatric conditions, the syndrome is presumed to result from a variety of disease mechanisms and to have multiple etiologies, ranging from psychological trauma or underlying neurological, endocrine, and metabolic disorders to postinfectious autoimmune and neuroinflammatory disorders, such as pediatric autoimmune neuropsychiatric disorder associated with streptococcal infections (PANDAS), cerebral vasculitis, neuropsychiatric lupus, and others (Swedo et al. 2012; Chang et al. 2015). In cohorts of well-characterized PANS patients, evidence of postinfectious autoimmunity and/or neuroinflammation is found in more than $80 \%$ of cases (Frankovich et al. 2015; Murphy et al. 2015; Swedo et al. 2015). Thus, treatment of PANS depends on three complementary modes of intervention:

1. Treating the symptoms with psychoactive medications, psychotherapies (particularly cognitive behavioral therapy), and supportive interventions.

2. Removing the source of the inflammation with antimicrobial interventions.

3. Treating disturbances of the immune system with immunomodulatory and/or anti-inflammatory therapies.

\section{Methods}

Members of the PANS/PANDAS Research Consortium (PRC) began development of the treatment guidelines in May 2014 at a meeting held at the National Institutes of Health in Bethesda, Maryland. Refinements and modifications were made for the ensuing 2 years by three workgroups that separately addressed (1) use of psychiatric medications and behavioral interventions, (2) use of antimicrobials, and (3) use of anti-inflammatory and immunomodulating therapies (see Fig. 1). The workgroups followed similar procedures, first reviewing the published literature and drawing upon their combined clinical experience with more than 1000 children with PANS/PANDAS to formulate an initial set of recommendations, which were then sent to a separate group of expert clinicians for critical review and comment.

The review panels included not only clinicians with expertise in the diagnosis and treatment of PANS/PANDAS but also experts in the fields of child psychiatry, pediatrics, infectious diseases, microbiology, neurology, neuroimmunology, immunology, and rheumatology. The reviewers' suggestions were incorporated into a revised set of guidelines, which was also circulated for comment and correction before being submitted to the PRC for adoption. In a few instances, consensus could not be reached on a single approach to treatment, so the PRC opted to include both options for intervention (e.g., whether or not to use antibiotics in children without documented infections). Thus, the three sets of guidelines truly represent "best practices" from across the country.

We expect that these recommendations will evolve over time, as controlled trials begin to test the efficacy of the various treatment combinations, and clinical experience broadens and deepens. In the interim, we wish to acknowledge the valuable contributions of the following individuals: Dritan Agalliu, Gail Bernstein, David Brick, Reuven Bromberg, Kayla Brown, Kiki Chang, Harry Chugani, Michael Cooperstock, Dan Coury, Madeleine Cunningham, Tyler Cutforth, Michael Daines, Russell Dale, Josephine Elia, Faith Kristine Espinoza, Bahare Farhadian, Robert Fryer, Hayley Gans, Daniel Geller, Jay Giedd, Paul Grant, Earl Harley, Joseph Hernandez, Rebecca Hommer, Mady Hornig, Cynthia Kapphahn, Miro Kovacevic, Elizabeth Latimer, Jill Leon, Bryan King, James Leckman, Eyal Muscal, Mark Pasternack, Sydney Rice, Alan Rosenberg, Terence Sanger, Richard Shaw, Michael Sherman, Janell Sherr, Margo Thienemann, Wendy Vargas, Theresa Willet, Kyle Williams, and Yujuan Zhang.

\footnotetext{
${ }^{1}$ Section on Behavioral Pediatrics, Intramural Research Program, National Institute of Mental Health, Bethesda, Maryland.

${ }^{2}$ Divisions of Pediatric, Department of Allergy, Immunology, and Rheumatology, Palo Alto, California.

${ }^{3}$ Stanford PANS Clinic and Research Program at Lucile Packards Children's Hospital, Stanford School of Medicine, Palo Alto, California.

${ }^{4}$ Department of Pediatrics, Rothman Center for Neuropsychiatry, University of South Florida, St. Petersburg, Florida.
} 


\section{Use of the Treatment Guidelines}

An overview of the management of PANS/PANDAS is presented in the Table 1.

As shown, the first step is always a comprehensive evaluation, which should include a complete medical and psychiatric history, physical examination, laboratory testing of blood [and possibly, cerebrospinal fluid (CSF)], and selected paraclinical evaluations, such as magnetic resonance imaging, electrocardiogram/ echocardiography, electroencephalography, and polysomnography (see Chang et al. 2015 for detailed description). The diagnosis of PANS should be made only when "symptoms are not better explained by a known neurological or medical disorder," such as Sydenham chorea, autoimmune encephalitis, neuropsychiatric lupus, central nervous system vasculitis, and others. By definition, PANS is always a diagnosis of exclusion. Thus, clinicians are encouraged to begin with a broad differential diagnosis and narrow it to PANS only after eliminating all other possibilities (Swedo et al. 2012; Chang et al. 2015).

With an accurate diagnosis in hand, the clinician should then evaluate the patient's clinical presentation and determine which symptoms are the highest priority for treatment with psychotropic medications and/or behavioral therapies. For some children, the PANS-related separation anxiety and obsessive thoughts create the most distress and interference, whereas other children (and their parents) are most troubled by emotional lability, rages, and impulsivity. Guidelines for addressing each of the PANS symptom domains are provided in Part I: "Psychiatric and Behavioral Interventions" (Thienemann et al. 2017).

Symptomatic treatments were purposefully given primary status among the three sets of guidelines, as we advocate starting them as soon as the PANS diagnosis is made. Often, the benefits of psychotropic medications are not seen for 8-12 weeks after an optimum dosage level has been achieved (through a slow and cautious upward taper). Behavioral interventions also take time to work, producing tangible benefits only after the child has completed 1216 sessions of therapy. Thus, to reduce the length of time that a child will suffer from his or her PANS symptoms, psychiatric interventions should begin as quickly as possible. Psychoeducation

Table 1. General Principles for Treating Pediatric Acute-Onset Neuropsychiatric Syndrome

1. Establish that PANS is the correct "diagnosis of exclusion" by completing a comprehensive diagnostic evaluation (Chang et al. 2015).

2. Provide symptomatic relief with psychiatric medications and behavioral interventions, prioritizing treatment of symptoms causing the greatest distress and interference (Thienemann et al. 2017).

3. Treat underlying infections and consider use of therapeutic or prophylactic antibiotics (Cooperstock et al. 2017).

4. Treat symptoms resulting from neuroinflammation or postinfectious autoimmunity with anti-inflammatory or immunomodulatory therapies, chosen on the basis of symptom severity and disease trajectory (Frankovich et al. 2017).

5. Evaluate effectiveness of the treatment regimen at frequent intervals, making modifications as warranted by improvement or worsening of symptoms.

6. Treatment can be tapered downward or stopped when symptoms resolve. However, treatment may be necessary again at some point in the future, given the relapsing-remitting nature of PANS symptoms.

PANS, pediatric acute-onset neuropsychiatric syndrome.

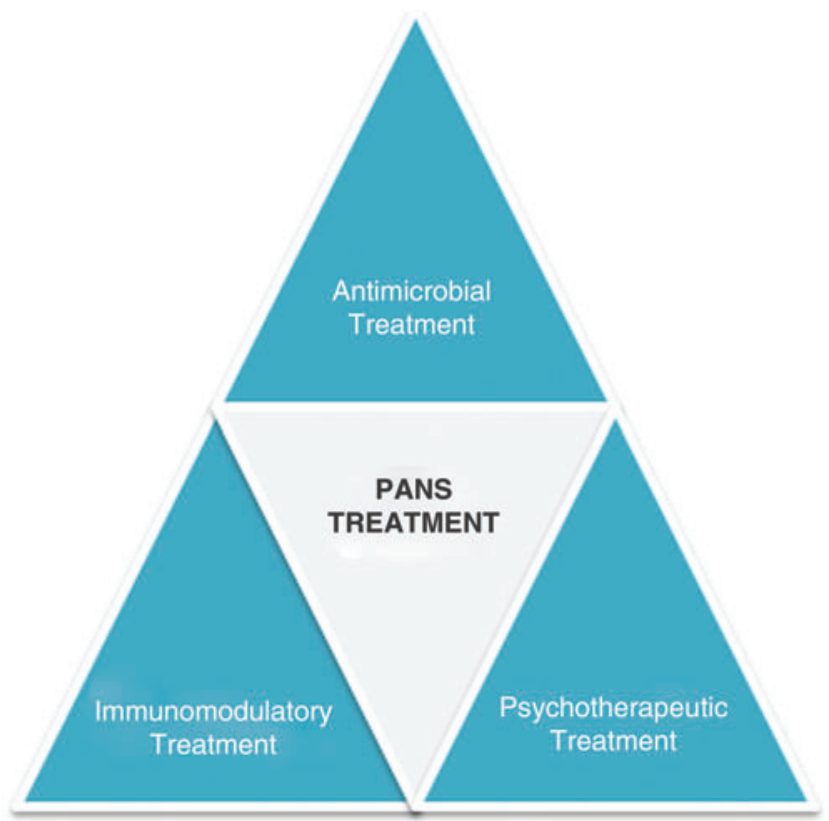

FIG. 1. The PANS treatment triangle. PANS, pediatric acuteonset neuropsychiatric syndrome. Color images available online at www.liebertpub.com/cap

and training in behavioral interventions should also be started early in the course of illness so that caregivers have the tools they need to contain and manage the PANS-related symptoms in the home.

Immune therapies are the second cornerstone in the treatment of PANS, as detailed in Part II of the Guidelines: "Use of Immunomodulatory Therapies" (Frankovich et al. 2017). Although immune treatments should be considered for all PANS patients, they are used only in cases wherein there is clear evidence of neuroinflammation or postinfectious autoimmunity as the underlying cause for the PANS symptoms ( $\sim 80 \%$ of patients). Such evidence might come from the physical examination, laboratory assays, or paraclinical assessments, as described in the PANS diagnostic guidelines (Chang et al. 2015).

The guidelines for use of anti-inflammatory medications and/or immune modulation in immune-related PANS are based on decades of experience with their use in the treatment of other postinfectious autoimmune conditions (such as asthma, reactive arthritis, and postinfectious encephalitis) and neuroinflammatory disorders (including neuropsychiatric lupus, cerebral vasculitis, and the neurological manifestations of Sjogren's syndrome, among others). Anti-inflammatory and immunomodulatory therapies have proven useful for these conditions, even when the inciting infection has long since been cleared (Van Mater 2014; Dale et al. 2017) and biomarkers of inflammation are no longer found in blood or CSF (Delalande et al. 2004; Benseler and Silverman 2007). In such instances, the only evidence that there is ongoing neuroinflammation may be the therapeutic effects of anti-inflammatory and immunomodulatory interventions.

The use of immune therapy is not without risks, and continued immunotherapy is warranted only when treatment produces clear and convincing symptomatic improvements. Clinicians should continually evaluate the impact of the interventions and stop therapy when the PANS symptoms no longer respond to the chosen immune intervention. If PANS symptoms fail to improve after intensive interventions, such as high-dose corticosteroids, consideration should be 
given to the possibility that the current symptoms represent damaged neural circuits, rather than ongoing neuroinflammation. In those cases, immunotherapy should be stopped, and therapeutic efforts redirected toward rehabilitation and supportive therapies (Haupt et al. 2005; Murphy et al. 2006; Storch et al. 2006; Muscal and Brey 2010; Nadeau et al. 2015; Thienemann et al. 2017).

The final leg of the PANS treatment triangle is use of antimicrobials, as described in Part III of the Management Guidelines: "Treatment and Prevention of Infections" (Cooperstock et al. 2017). An initial course of antibiotics is recommended for all PANS cases, including those without documented infections, as is done for patients with acute rheumatic fever (Gerber et al. 2009). This recommendation is supported by an emerging literature reporting therapeutic benefits of antibiotics in PANS (with and without an infectious trigger), including reports of patients who have experienced a complete and lasting remission of symptoms during antibiotics treatment (Murphy and Pichichero 2002; Snider et al. 2005; Falcini et al. 2013; Frankovich et al. 2015; Murphy et al. 2015, 2017; Mahony et al. 2017).

Evidence supporting the use of therapeutic antibiotics in PANS/ PANDAS is reviewed, as are the adverse effects that must be considered in determining the risk-benefits ratio for an individual patient. The guidelines also provide recommendations for the use of long-term prophylactic antibiotics in PANS cases with and without infectious triggers, including factors that must be considered before starting (or stopping) the prophylaxis.

To summarize, treatment of PANS involves a three-pronged approach (see Fig. 1) that utilizes psychiatric medications when appropriate to provide symptomatic relief, antibiotics to eliminate the source of neuroinflammation, and anti-inflammatory and immune modulating therapies to treat disturbances of the immune system. The specific elements chosen for a child's treatment regimen are influenced by results of the physical examination and laboratory testing, as well as by the course and severity of PANS symptomatology. Children with severe or life-threatening symptoms, and those with complex clinical presentations, may require specialized treatment by an experienced transdisciplinary team of PANS/ PANDAS clinicians. In most cases, however, the child's primary care provider will be able to treat the PANS symptoms effectively, with guidance from these three sets of treatment recommendations.

\section{Acknowledgment}

This work was supported (in part) by the Intramural Research Program of the National Institute of Mental Health.

\section{Disclosures}

S.E.S. and J.F. have no financial conflicts or interests to disclose. T.K.M. reports research support from the following: Centers for Disease Control, National Institute of Mental Health, Massachusetts General Hospital, PANDAS Network, Shire Pharmaceuticals, Pfizer, Inc., Hoffmann-La Roche Ltd., Sunovion Pharmaceuticals, Auspex Pharmaceuticals, Neurocrine Pharmaceuticals, and Allergan. She is on unpaid advisory boards for the International OCD Foundation, Tourette Association of America, and PANDAS Network.

\section{References}

Benseler S, Silverman E: Review: Neuropsychiatric involvement in pediatric systemic lupus erythematosus. Lupus 16:564-571, 2007.

Chang K, Frankovich J, Cooperstock M, Cunningham MW, Latimer ME, Murphy TK, Pasternack M, Thienemann M, Williams K,
Walter J, Swedo SE: Clinical evaluation of youth with pediatric acute-onset neuropsychiatric syndrome (PANS): Recommendations from the 2013 PANS Consensus Conference. J Child Adolesc Psychopharmacol 25:3-13, 2015.

Cooperstock M, Swedo SE, Pasternack M, Murphy TK; members of the PANS/PANDAS Clinical Research Consortium. Clinical Management of Pediatric Acute-onset Neuropsychiatric Syndrome (PANS): Part III-Treatment and Prevention of Infections. J Child Adolesc Psychopharmacol 2017. [Epub ahead of print]. DOI: 10.1089/cap.2016.0151.

Dale RC, Gorman MP, Lim M: Autoimmune encephalitis in children: Clinical phenomenology, therapeutics, and emerging challenges. Curr Opin Neurol 30:334-344, 2017.

Delalande S, de Seze J, Fauchais A-L, Hachulla E, Stojkovic T, Ferriby D, Dubucquoi S, Pruvo J-P, Vermersch P, Hatron P-Y: Neurologic manifestations in primary Sjögren syndrome: A study of 82 patients. Medicine 83:280-291, 2004.

Falcini F, Lepri G, Rigante D, Bertini F, Matucci Cerinic M: PReSFINAL-2252: Descriptive analysis of pediatric autoimmune neuropsychiatric disorder associated with streptococcus infection (PANDAS) in a cohort of 65 Italian patients.Pediatr Rheumatol 11: P242, 2013.

Frankovich J, Thienemann M, Pearlstein J, Crable A, Brown K, Chang K. Multidisciplinary clinic dedicated to treating youth with pediatric acute-onset neuropsychiatric syndrome: Presenting characteristics of the first 47 consecutive patients. J Child Adolesc Psychopharmacol 25:38-47, 2015.

Frankovich J, Thienemann M, Rana S, Chang K: Five youth with pediatric acute-onset neuropsychiatric syndrome of differing etiologies. J Child Adolesc Psychopharmacol 25:31-37, 2015.

Frankovich J, Swedo S, Murphy T, Dale RC, Agalliu D, Williams K, Daines M, Hornig M, Chugani H, Sanger T, Muscal E, Pasternack M, Cooperstock M, Gans H, Zhang Y, Cunningham M, Bernstein G, Bromberg R, Willett T, Brown K, Farhadian B, Chang K, Geller D, Hernandez J, Sherr J, Shaw R, Latimer E, Leckman J, Thienemann M: Clinical management of Pediatric Acute-onset Neuropsychiatric Syndrome (PANS): Part II-use of immunomodulatory therapies. J Child Adolesc Psychopharmacol 2017. [Epub ahead of print]. DOI: 10.1089/cap.2016.0148.

Gerber MA, Baltimore RS, Eaton CB, Gewitz M, Rowley AH, Shulman ST, Taubert KA. Prevention of rheumatic fever and diagnosis and treatment of acute streptococcal pharyngitis. Circulation 119:1541-1551, 2009.

Haupt M, Millen S, Jänner M, Falagan D, Fischer-Betz R, Schneider M: Improvement of coping abilities in patients with systemic lupus erythematosus: A prospective study. Ann Rheum Dis 64:16181623, 2005.

Mahony T, Sidell D, Gans H, Brown K, Farhadian B, Gustafson M, Sherr J, Thienemann M, Frankovich J: Improvement of psychiatric symptoms in youth following resolution of sinusitis. Int J Pediatr Otorhinolaryngol 92:38-44, 2017.

Murphy ML, Pichichero ME: Prospective identification and treatment of children with pediatric autoimmune neuropsychiatric disorder associated with group A streptococcal infection (PANDAS). Arch Pediatr Adolesc Med 156:356-361, 2002.

Murphy TK, Parker-Athill EC, Lewin AB, Storch EA, Mutch PJ: Cefdinir for recent-onset pediatric neuropsychiatric disorders: A pilot randomized trial. J Child Adolesc Psychopharmacol 25:57-64, 2015.

Murphy TK, Patel PD, McGuire JF, Kennel A, Mutch PJ, ParkerAthill EC, Hanks CE, Lewin AB, Storch EA, Toufexis MD, Dadlani $\mathrm{GH}$, and Rodriguez $\mathrm{CA}$. Characterization of the pediatric acute-onset neuropsychiatric syndrome phenotype. J Child Adolesc Psychopharmacol 25:14-25, 2015. 
Murphy TK, Storch EA, Strawser MS: Selective serotonin reuptake inhibitor-induced behavioral activation in the PANDAS subtype. Primary Psych 13:87, 2006.

Murphy TK, Brennan E, Johnco C, Parker-Athill, EC, Miladinovic B, Storch EA, Lewin AB: A double blind randomized placebocontrolled pilot study of azithromycin in youth with acute obsessive compulsive disorder. J Child Adolesc Psychopharmacol 2017. [Epub ahead of print]. DOI: 10.1089/cap.2016.0190.

Muscal E, Brey RL: Neurologic manifestations of systemic lupus erythematosus in children and adults. Neurol Clin 28:61-73, 2010.

Nadeau JM, Jordan C, Selles RR, Wu MS, King MA, Patel PD, Hanks CE, Arnold EB, Lewin AB, Murphy TK: A pilot trial of cognitive-behavioral therapy augmentation of antibiotic treatment in youth with pediatric acute-onset neuropsychiatric syndromerelated obsessive-compulsive disorder. J Child Adolesc Psychopharmacol 25:337-343, 2015.

Snider LA, Lougee L, Slattery M, Grant P, Swedo SE: Antibiotic prophylaxis with azithromycin or penicillin for childhood-onset neuropsychiatric disorders. Biol Psychiatry 57:788-792, 2005.

Storch EA, Murphy TK, Geffken GR, Mann G, Adkins J, Merlo LJ, Duke D, Munson M, Swaine Z, Goodman WK: Cognitivebehavioral therapy for PANDAS-related obsessive-compulsive disorder: Findings from a preliminary waitlist controlled open trial. J Am Acad Child Adolesc Psychiatry 45:1171-1178, 2006.

Swedo SE, Leckman JF, Rose NR: From research subgroup to clinical syndrome: Modifying the PANDAS criteria to describe PANS (pediatric acute-onset neuropsychiatric syndrome). Pediatr Therapeut 2:1-8, 2012.

Swedo SE, Seidlitz J, Kovacevic M, Latimer ME, Hommer R, Lougee L, Grant P: Clinical presentation of pediatric autoimmune neuropsychiatric disorders associated with streptococcal infections in research and community settings. J Child Adolesc Psychopharmacol 25:26-30, 2015.

Thienemann MM, Tanya K, Leckman J, Shaw R, Williams K, Kapphahn C, Frankovich J, Geller D, Bernstein G, Chang K, Swedo SE: Clinical management of pediatric acute-onset neuropsychiatric syndrome (PANS): Part I-Psychiatric and behavioral interventions. J Child Adolesc Psychopharmacol 2017. [Epub ahead of print]. DOI: $10.1089 /$ cap.2016.0145.

Van Mater H: Pediatric inflammatory brain diseases: A diagnostic approach. Curr Opin Rheumatol 26:553-561, 2014.

Address correspondence to:

Susan E. Swedo, MD

Section on Behavioral Pediatrics

Intramural Research Program

National Institute of Mental Health

10 Center Drive-MSC 1255

Bethesda, MD 20892-1255

E-mail: swedos@mail.nih.gov 